\section{Eye movements and decrement in the Oppel-Kundt illusion*}

\author{
STANLEY COREN and PAUL HOENIG \\ New School for Social Research, New York, New York 10011
}

Two groups of $15 \mathrm{Ss}$ each observed the Oppel-Kundt illusion, in which a divided extent appears longer than an undivided extent. The group which made saccadic eye movements over the figure showed significant decrement of the illusion, while the group which maintained steady fixation showed no decrement. These results support an interpretation which maintains that information from eye-movement errors provides data as to the nature and extent of the illusion, thus leading to decrement.

Since Judd's work in 1902, it has been generally accepted that with prolonged visual inspection there is a decline in the magnitude of the Mueller-Lyer illusion. Although decrement of the Mueller-Lyer illusion has been verified many times (Day, 1962; Lewis, 1908; Mountjoy, 1958), until recently there was little evidence that illusion decrements would be found in other figures. Recent work by Coren and Girgus (1972) indicates that a number of other illusion figures diminish with inspection.

While evidence for the widespread existence of illusion decrement is now accruing, little is known about the mechanisms which support the disappearance of the illusory effect. One of the most attractive explanations offered to date bases decrement upon the information obtained by erroneous eye movements emitted while inspecting the illusory figure. Thus, in an illusion of extent, if the eye movements are emitted on the basis of perceived size, there will be consistent overshooting of the ends of apparently longer segments and undershooting of apparently shorter segments of the illusion figure. These erroneous eye movements should then provide information about the nature of the distortion. Such systematically erroneous eye movements have been demonstrated for the Mueller-Lyer illusion (Judd, 1905; Stratton, 1908; Festinger, White, \& Allyn, 1968) and the Poggendorff illusion (Cameron \& Steele, 1905). In the absence of eye movements, there should be little information about the nature of the distortion and hence little reason to modify the percept. Consistent with this prediction, Festinger, White, and Allyn (1968) have shown that there is more illusion decrement when saccadic eye movements are made over the Mueller-Lyer figure than when fixation

*We would like to thank Joan S. Girgus for her reading of the initial manuscript. This work was supported in part by NIH Grant 16327, awarded to Leon Festinger. long and subtended a visual angle of 4 deg. The comparison was an adjustable undivided line, colinear with the standard and set in a tongue and groove arrangement. A millimeter scale was affixed to the back of the adjustable extent. The stimulus configuration is illustrated in the inset in Fig. 1.

\section{SUBJECTS AND PROCEDURE}

Thirty paid volunteers were assigned randomly to either a fixation or a saccadic eye-movement group. All Ss began by setting the adjustable line so that it was apparently equal to the divided line twice, counterbalanced as to starting length of the comparison. The two lines were then set to physically equal, and the fixate group was required to maintain fixation on the junction between the divided and undivided space. The saccadic eye-movement group was required to move their eyes continually from the end to the junction to the other end of the figure, and then back. Another pair of measurements was taken at each 2-min interval until an inspection period of $6 \mathrm{~min}$ had elapsed. effect on the decrement of an illusion of extent other than the Mueller-Lyer. The selected illusion figure was the Oppel-Kundt illusion, in which a divided space is seen as longer than an undivided space.

\section{STIMULI AND APPARATUS}

The illusion figure consisted of a divided space and an adjustable undivided space. The divided space consisted of six equally spaced black dots, each subtending $3 \mathrm{~min}$ of arc. The entire divided extent was $10 \mathrm{~cm}$

\section{RESULTS AND DISCUSSION}

Figure 1 shows the illusion magnitude plotted in percentage of illusion, where the mean of the first settings (preinspection) is defined as $100 \%$. The prediction being made is that there will be more decrement in the illusion for the eye-movement group than for the fixation group. Inspection of the figure reveals that this is the obtained result. For the saccadic eye-movement group, there is

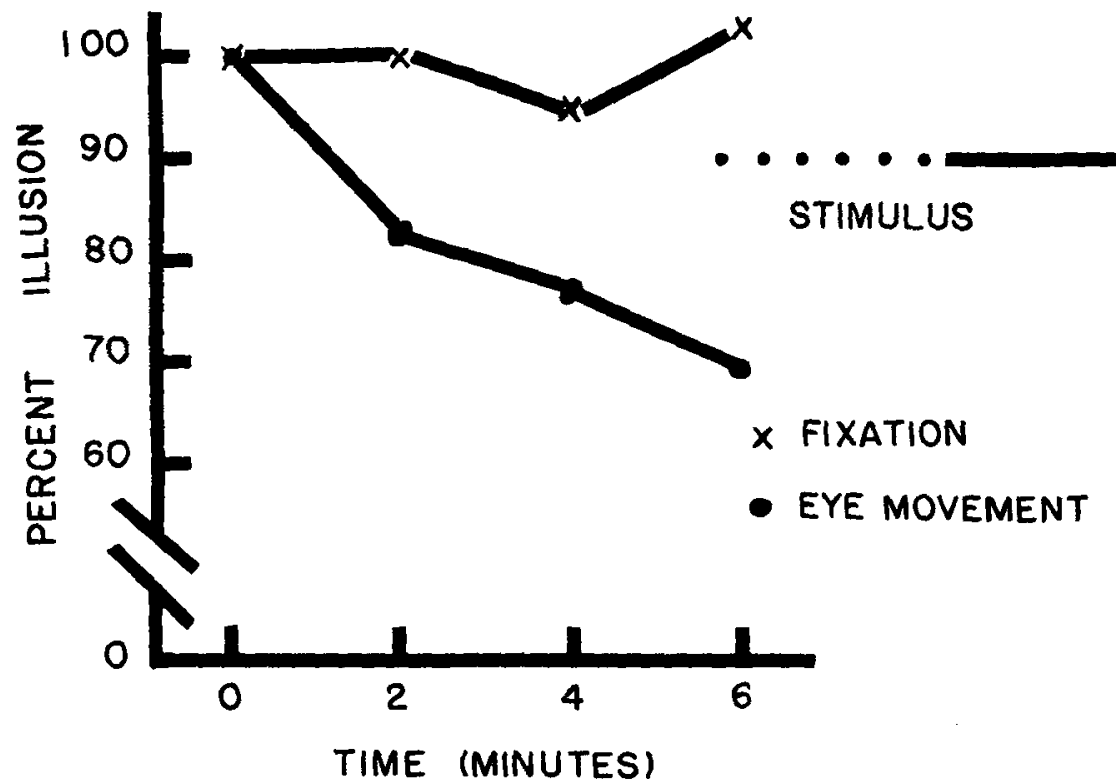

Fig. 1. Percent of illusion is plotted against inspection time in minutes. The inset shows the Oppel-Kundt stimulus configuration used in this experiment. 
a significant decrease in illusion magnitude as a function of inspection time, with $F=10.38$, df $=3 / 42$, $\mathrm{p}<.01$. For the fixation group, no significant decrement is found $(F=$ 0.43 , df $=3 / 42$ ). Another way of looking at these data that makes the same point is to note that there is no difference between the groups at the initial measure $(t=0.255$, df $=28$ ), while after $6 \mathrm{~min}$ of inspection there is significantly less illusion for the saccadic eye-movement group than for the group which emitted no eye movements over the figure $(t=2.46$, df $=28, p<.05$ ).

The finding of a decrement of the Oppel-Kundt illusion with free eye movements extends the range of illusions known to decrement with inspection beyond the set of intersecting line figures studied by Coren and Girgus (1972). The difference in the rate of decrement as a function of the presence or absence of eye movements replicates the findings obtained with the Mueller-Lyer illusion by Festinger, White, and Allyn (1968), since inspection with free eye movements yields decrement, while if only one point is fixated during inspection no decrement occurs.

It is important to note that these data only implicate eye movements as a mechanism for decrement. They do not necessarily indicate that eye movements are responsible for the initial perception of the illusion. It should be evident, however, that theorists who have maintained that visual illusions depend upon overt eye movements (Wundt, 1897; Biervliet, 1896), implicit eye movements (Washburn, 1916), or upon the set of efferent readinesses evoked by the incoming visual stimulation (Festinger, Burnham, Ono, \& Bamber, 1968; Festinger, White, \& Allyn, 1968) can easily explain the larger decrement in the presence of eye movements. According to this class of theory, the decrement results from a restructuring of the relationship between the efference and the afference as a result of the information about the distortion obtained from erroneous eye movements. As the eye movements become more accurate, the illusion which was initially dependent upon them would naturally be expected to diminish.

There is another class of theories which should also have no difficulty explaining the facilitating effect of eye movements on decrement of the illusion. These theories, which are judgmental in nature, contend that the illusion results from asymmetries in the distribution of attention (Carr, 1935; Erlebacher \& Sekuler, 1969; Piaget, 1969) or are determined by the cognitive comparison of one part of the array with another, resulting in a sharpening of perceived differences (Helmholtz, 1962; Coren, 1971). Eye movements represent the only way in which an $O$ can directly interact with the illusion stimulus. Since the eye movements will be directed on the basis of the initial illusory percept, they will tend to be systematically erroneous, and these resultant eye-movement errors will serve to instruct the $O$ as to the nature of the distortion. This information about the presence of a distortion, and its direction and extent, may now be incorporated into the judgmental process, resulting in a redistribution of attention, a change in the weighting of inducing elements, or a restructuring of the comparison process. Such changes in the process which lead to elimination of the initial judgmental error will, of course, produce a reduction in illusion magnitude. Thus, it becomes clear that, for both eye-movement theories and judgmental theories of visual-geometric illusions, the actively moving and exploring eye provides information indicating the nonveridicality of the initial percept. This information, garnered from eye-movement errors, is fed back into the perceptual system, resulting in closer correspondence between the percept and the distal stimulus, and hence a decrement in the initial illusion magnitude.

\section{REFERENCES}

BIERVLIET, J. J. Van. Nouvelles mesures des illusions visuelles chez les adultes et les enfants. Revue Philosophique, 1896 , 41, 169-181.

CAMERON, E. H., \& STEELE, W. M. The Poggendorff illusion. Psychological Review Monograph Supplement, 1905, 7 (No. 29), 83-111

CARR, H A An introduction to space perception. New York: Longmans, Green, 1935 .

COREN, S. A size contrast illusion without physical size difference. American Joumal of Psychology, 1971, 84, 565-566.

COREN, S., \& GIRGUS, J. S. Illusion decrement in intersecting line figures. Psychonomic Science, 1972, 26, 108-110.

DAY, R. H. The effects of repeated trials and prolonged fixation on error in the Müller-Lyer figure. Psychological Monographs, 1962, 76(14, Whole No. 533).

ERLEBACHER, A., \& SEKULER, $R$. Explanation of the Muller-Lyer illusion: Confusion theory examined. Journal of Experimental Psychology, 1969, 80, 462-467.

FESTINGER, L., BURNHAM, C. A., ONO, $H$, \& BAMBER, D. Efference and the conscious experience of perception. Journal of Experimental Psychology, 1967. Monograph Supplement, 74(4, Whole No. 637).

FESTINGER, L.. WHITE, C. W., \& ALLYN $M$. R. Eye movements and decrement in the Muller-Lyer illusion. Perception \& Psychophysics, 1968, 3, 376-382.

HELMHOLTZ, H. von. Physiological optics. (Trans. P. C. Southall) New York: Dover, 1962.

JUDD, C. H. Practice and its effects on the perception of illusions. Psychological Review, 1902, 9, 27-39.

JUDD, $C$. $H$. The Müller-Lyer illusion. Psychological Review, 1905 7 (Monograph Supplement, whole No. 29).

LEWIS, E. O. The effect of practice on the perception of the Muller-Lyer illusion. British Journal of Psychology, 1908, 2, 294-306.

MOUNTJOY, P. T. Effects of exposure time and intertrial interval upon decrement to the Muller-Lyer illusion. Journal of Experimental Psychology, 1958, 56, 97-102.

PIAGET, J. The mechanisms of perception. (Trans. G. N. Seagrim) New York: Basic Books, 1969.

STRATTON, G. M. Symmetry, linear illusions, and the movements of the eye. Psychological Review, 1906, 13,82-96.

WASHBURN, M. F. Movement and mental imagery. Boston: Houghton Miffin 1916.

WUNDT, W. Outlines of psychology. (Trans. C. H. Judd) Leipzig: Engelmann, 1897.

(Accepted for publication April 21, 1972.) 